\title{
Brantz, Dorothee, Mauch, Christof, Tierische Geschichte : die Beziehung von Mensch und Tier in der Kultur der Moderne
}

\section{François Walter}

\section{OpenEdition}

Édition électronique

URL : http://journals.openedition.org/ifha/2109

DOI : $10.4000 /$ ifha. 2109

ISSN : 2198-8943

\section{Éditeur}

IFRA - Institut franco-allemand (sciences historiques et sociales)

\section{Référence électronique}

François Walter, «Brantz, Dorothee, Mauch, Christof, Tierische Geschichte : die Beziehung von Mensch und Tier in der Kultur der Moderne », Revue de l'IFHA [En ligne], Date de recension, mis en ligne le 01 janvier 2010, consulté le 22 septembre 2020. URL : http://journals.openedition.org/ifha/2109 ; DOI : https://doi.org/10.4000/ifha.2109

Ce document a été généré automatiquement le 22 septembre 2020.

(CIFHA 


\title{
Brantz, Dorothee, Mauch, Christof, Tierische Geschichte : die Beziehung von Mensch und Tier in der Kultur der Moderne
}

\author{
François Walter
}

1 Ce volume réunit une vingtaine de contributions issues d'un grand colloque international organisé en 2005. Un bon nombre de textes sont traduits de l'anglais, ce qui n'est pas trop étonnant puisque l'histoire culturelle des animaux est un champ de recherche très développé dans le monde anglo-américain. L'objectif est d'étudier les interactions entre l'homme et l'animal en mettant en évidence les aspects religieux, symboliques et philosophiques de différentes situations concrètes. Elles sont liées à la domestication et aux divertissements recourant à des animaux ainsi qu'à des pratiques sociales nouvelles développées par l'éthique de la protection. L'intérêt du livre est d'être centré sur les XIXe et XXe siècles, période sur laquelle on dispose de beaucoup moins d'études que pour les temps plus anciens.

2 La première partie s'intéresse aux significations sociales et culturelles de l'animal dans la société contemporaine. Il faut bien constater, en effet, que la recherche historique ne peut s'intéresser qu'à la manière dont les animaux sont représentés et perçus et, par la force des choses, assez peu à l'animal lui-même. Seuls les documents rédigés par l'homme nous en parlent ! C'est ainsi que $\mathrm{N}$. Rothfels décrit l'expérience concrète de l'éléphant, possible au XIXe siècle, puisqu'on commence à trouver les pachydermes dans les zoos vers 1865. Le public peut monter sur leur dos et donc les toucher, comme l'a fait aussi l'empereur Guillaume II à Hambourg en 1913 en touchant un rhinocéros. Si l'objectif était vraiment de faire l'histoire de l'animal pour lui-même, on devrait donc se demander à quel point nos propres perceptions et expériences ont une influence sur l'animal. Cette préoccupation de bonne méthode traverse à vrai dire tout le recueil sans trouver véritablement de piste convaincante pour la mettre en œuvre. Seuls des observations très fragmentaires peuvent faire avancer cet aspect de la problématique. 
Ainsi, les auteurs qui étudient le rôle du cheval dans le processus d'urbanisation aux États-Unis suggèrent que les chevaux ont leur manière à eux de se révolter en s'échappant de leurs écuries. Compte tenu des effectifs énormes qui sont nécessaires aux transports urbains, ces épisodes peuvent concerner quelques milliers de quadrupèdes.

Quatre communications sont consacrées à la construction d'une certaine image du chien : comment au XXe siècle, le chien de berger a été utilisé comme chien policier et même comme auxiliaire militaire avec une place particulière dans l'imaginaire nazi ; comment le chien a gagné sa fonction de compagnon auprès des enfants; ou encore comment les historiens peuvent retracer les biographies de certains canidés devenus célèbres parce qu'ils accompagnent des hommes politiques (les chiens des présidents) ou parce qu'ils ont été utilisés dans les expériences spatiales (les chiens cosmonautes).

4 Reste que la plupart des textes s'en tiennent à la construction de l'animal par l'homme. Toute la deuxième partie du livre étudie le cas des animaux sauvages. Ainsi, on découvre comment après l'arrivée d'un premier rhinocéros aux États-Unis s'est diffusée une image de sauvagerie et d'agressivité de cette espèce, évidemment fort éloignée de la réalité du paisible herbivore. Plus généralement, la présence de certaines espèces dans les ménageries sert à diffuser l'image de l'extension des possessions impériales partout dans le monde. Ainsi, les animaux sauvages sont importants dans l'autoreprésentation nationale des Britanniques. L'alligator est redouté en Amérique latine et réputé mangeur de chair humaine alors que les attaques sont plutôt rares. Cela n'empêche pas cette espèce d'avoir été promue au rang de symbole national en Floride.

5 La troisième partie évoque le discours juridique, politique et scientifique autour des animaux. Quelques contributions reprennent le dossier du darwinisme. On sait par exemple que les chiens de chasse de Darwin ont joué un certain rôle dans la genèse de ses idées sur la sélection. Le grand savant allait par ailleurs dans les zoos pour observer les singes.

6 Dans son article, 0 . Hochadel fait à ce propos l'hypothèse d'un lien entre la présence des grands singes primates dans les zoos et le débat sur l'évolutionnisme. Les premiers spécimens de primates ont été amenés en Europe au XVIIe siècle déjà pour le chimpanzé, au siècle suivant en ce qui concerne l'orang-outang, mais le premier gorille vivant est mentionné en 1847. C'est vers 1860 que l'on commence à s'interroger sur les rapports entre l'homme et ce type de singe. Ce qui inquiète l'opinion, c'est surtout l'idée que l'homme soit rabaissé au statut de singe, évolué sans doute mais tout de même. L'auteur de cette contribution passionnante démontre comment les visiteurs des zoos viennent rire des comportements des singes en cage comme pour mettre une distance et se persuader que finalement les hommes sont fort différents et bien supérieurs.

7 Quelques contributeurs examinent les enjeux plus politiques du rapport homme/ animal. On retiendra une étude basée sur les archives de la SDN à Genève qui révèle les activités d'un Bureau international humanitaire zoophile actif dès 1928. Il s'illustre notamment par son engagement contre les expérimentations de gaz de combat sur des bêtes. L'argument est que celui qui veut la paix doit aussi protéger les créatures les plus faibles.

8 Enfin, dans la quatrième partie du livre, des anthropologues, psychologues et historiens reprennent les questions plus générales concernant la problématique des recherches sur les relations entre l'homme et l'animal. Le constat est évident que l'on aborde 
toujours l'étude des animaux en projetant sur eux ce qu'on connaît des comportements humains (anthropomorphisme). Cela est particulièrement vrai dans le cas des mouvements qui prétendent protéger les animaux. Ne vaut-il pas mieux dès lors adopter une position épistémologique postmoderne et admettre comme postulat que nos représentations des animaux n'ont - a priori - guère de correspondance avec une quelconque réalité vécue par les animaux eux-mêmes. Le chapitre conclusif se termine sur des propos désabusés selon lesquels les animaux vont rester pour nous totalement insaisissables parce qu'il nous est impossible d'échapper non seulement à l'anthropomorphisme mais encore à l'anthropocentrisme.

9 François Walter (Université de Genève) 